
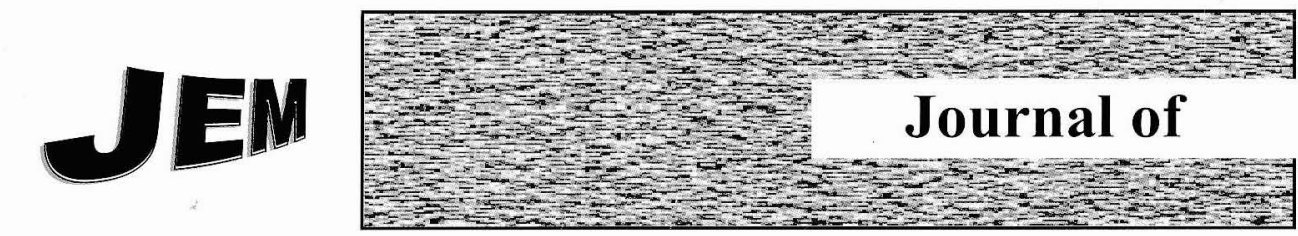

EDucational Management

A Bi-annual Publication of

THE INSTITUTE FOR EDUCATIONAL PLANNING AND ADMINISTRATION

(IEPA)

University of Cape Coast, Ghana

ISSN 0855 - $3343 \quad$ Vol. $6 \quad$ Nov. 2012 


\section{BARRIERS AFFECTING THE PROGRESS OF WOMEN FACULTY TOWARDS LEADERSHIP POSITIONS IN PUBLIC UNIVERSITIES IN GHANA}

\section{Janet Alberta Koomson}

Abstract

The study explores the barriers which impede the progress of women faculty towards leadership positions within the public universities in Ghana. The multi-cited case study was designed to investigate the barriers that affect the progress of women faculty. One hundred and forty eight respondents from the six public universities made up the sample. Data for the study were collected using the questionnaire. The study revealed that most women faculty aspired for leadership positions within their universities. However, barriers such as role conflict, lack of publication, non existence of mentors and role models affected their progress towards leadership positions. Some of the effects of these barriers were lack of promotion, time constraints and marital strain.

\section{Introduction}

The low representation of women in Ghana's public universities, combined with their small numbers at higher professional levels can be attributed to several factors, which are barriers to their progress towards leadership positions. According to Brown and Barbosa (2001), barriers are obstacles that prevent the forwar' movement or any event or condition that makes career progress difficult. Stephenson and Burge (1997) and Brown and
Barbosa, explain that the onset of such barriers frequently begins when women are children, and are reinforced throughout women's schooling, college, and work, and become more complex over time. They further state that barriers are significant factors in the career development process. This has support from Swanson and Woitke (1997) who indicate that barriers partially explain the gap between the abilities of women and their achievements, and this could explain the inhibitions of women's career aspirations. Some of these barriers are role conflict, gender stereotyping and Ghanaian cultural beliefs, values and the socialization processes. In this regard, it can be stated that institutions of higher education are microcosms of a gendered inequitable society. Women trying to advance their careers have. historically, encountered a "glass ceiling". Torlay, in many ways, they encounter a "glass ceiling" where the "inferiority" of women continues to reflect and enlarge the men who maintain positions of prestige and leadership. The existence of a glass ceiling within organizations is a reflection of the inequality between genders that exist in the social and economic spheres. Although a change in social attitudes is being sought by institutions, "the predominance of males in the top managerial positions tends to perpetuate the glass ceiling" (Wylie, 1996, p. 23). Therefore, females are often rationalized as not 
possessing the suitable managerial experience that is needed at top level leadership.

In Ghana, the professional lives of most women are centered within a male-dominated society. In their book, "Women's Ways of Knowing", Belenky, Clinchy, Goldberger, and Tarule (1997) argued that the silenced nature of women, particularly in academia, exists because of the historical male-dominated culture resident there. According to them, "silent women have little awareness of their intellectual capabilities and they live selfless and voiceless, at the behest of those around them" (p. 134). Women's lack of access to leadership positions indicate significant gender issues at the top level of leadership in Ghana's public universities.

Although low in numbers, women have been part of Ghanaian university faculties for a long time. The problem they have encountered has been progress in their academic career. While there are no laws in Ghana discriminating against women's involvement in socio-economic development, there are numerous areas where discriminatory practices exist as a consequence of the conditions of women's work, cultural beliefs and attitudes, value systems and behavioral norms, folklore and folksongs. Ghana's social system and traditions have operated against women leadership and as such have given men greater leverage in education, training, greater political and decision-making powers, thereby perpetuating women's inferior status. Although human rights (encompassing women's rights) are enshrined in the constitution of Ghana, it is up to individual institutions and organizations to enact gender- related policies, procedures, and practices within their work context. Ghana has six public universities made up of University of Ghana (Legon), Kwame Nkrumah University of Science and Technology (KNUST), University of Cape Coast (UCC), University of Education, Winneba (UEW), University of Development Studies (UDS) and University of Mines and Technology (UMAT). Unfortunately, statistics from these universities show that women are in the minority with regard to the various faculty ranks. Table 1 shows a detailed comparison of female and male faculty members and their ranks in Ghana's public universities. 
Table 1: Faculty Statistics of Public Universities in Ghana

\begin{tabular}{|c|c|c|c|c|c|c|}
\hline University & Gender & Professor & Asso. Prof & Snr. Lec. & Lecturer & Total \\
\hline \multirow[t]{3}{*}{ Legon } & $M$ & 66 & 83 & 158 & 327 & 634 \\
\hline & F & 5 & 20 & 43 & 50 & 118 \\
\hline & Total & 71 & 103 & 201 & 377 & 752 \\
\hline \multirow[t]{3}{*}{ KNUST } & M & 21 & 48 & 139 & 442 & 650 \\
\hline & $\mathrm{F}$ & 2 & 4 & 21 & 34 & 61 \\
\hline & Total & 23 & 52 & 160 & 476 & 711 \\
\hline \multirow[t]{3}{*}{ UCC } & M & 13 & 45 & 77 & 215 & 350 \\
\hline & $\mathrm{F}$ & - & 3 & 6 & 33 & 42 \\
\hline & Total & 13 & 48 & 83 & 254 & 392 \\
\hline \multirow[t]{3}{*}{ UEW } & M & 7 & 17 & 57 & 157 & 238 \\
\hline & $\mathrm{F}$ & 2 & 1 & 11 & 35 & 43 \\
\hline & Total & 9 & 18 & 68 & 192 & 281 \\
\hline \multirow[t]{3}{*}{ UDS } & M & 2 & 1 & 14 & 142 & 159 \\
\hline & $\mathrm{F}$ & - & - & 1 & 9 & 10 \\
\hline & Total & 2 & 2 & 17 & 151 & 169 \\
\hline \multirow[t]{3}{*}{ UMAT } & M & 3 & 3 & 11 & 33 & 50 \\
\hline & $\mathrm{F}$ & - & - & 1 & 4 & 5 \\
\hline & Total & 3 & 3 & 12 & 37 & 55 \\
\hline
\end{tabular}

Source: University Annual Statistics (2008).

Table 1 provides an indication of females within the various ranks as compared to men. It is evident that there are few women within the higher ranks (Professor and Associate Professor) who could be considered for the position of Vice Chancellor. The University of Ghana has 25 women, Kwame Nkrumah University has six, and University of Cape Coast and University of Education, Winneba, have three each, who would meet the rank qualification for Vice Chancellor. These low numbers of women represented at these levels limits the probability that a female will be selected to the position of VC.

In Ghanaian universities, leadership positions open to women faculty (as 
well as men) are the Vice Chancellor, Dean of faculty and Head of Department (HoD). However, from the statistics of the various universities, these positions are dominated by men. Table 2 illustrates this reality.
Table 2 shows that there is no woman Pro VCs in any of the public universities in Ghana. UMAT, and UDS have no women who are Deans. UEW and UCC have one each, Legon has two and KNUST has the highest

\begin{tabular}{llcccc}
\hline University & Gender & VC & Pro VC & Dean & HoD \\
\hline Legon & M & 1 & 1 & 12 & 84 \\
& F & 0 & 0 & 2 & 17 \\
\multirow{3}{*}{ KNUST } & Total & 1 & 1 & 14 & 104 \\
& M & 1 & 1 & 18 & 82 \\
\multirow{3}{*}{ UCC } & F & 0 & 0 & 4 & 11 \\
& Total & 1 & 1 & 22 & 93 \\
& M & 0 & 1 & 7 & 39 \\
UEW & F & 1 & 0 & 1 & 2 \\
& Total & 1 & 1 & 8 & 41 \\
& M & 1 & 1 & 8 & 34 \\
UDS & F & 0 & 0 & 1 & 6 \\
& Total & 1 & 1 & 9 & 40 \\
& M & 1 & 1 & 7 & 25 \\
\multirow{3}{*}{ UMAT } & F & 0 & 0 & 0 & 0 \\
& Total & 1 & 1 & 7 & 25 \\
& M & 1 & 1 & 2 & 6 \\
& F & 0 & 0 & 0 & 1 \\
& Total & 1 & 1 & 2 & 7 \\
\hline
\end{tabular}

Source: University annual statistics (2008).

number of four. In considering HoDs, Table 2 shows the small numbers of women as compared to men who hold this position. UDS has no woman HoD, with UMAT having only one. UCC has two, UEW six, KNUST eleven and Legon has the largest number of seventeen. There is one woman VC (UCC), the first in the history of public universities in Ghana, which is a recent development (2008). However, in proportion to men, it can be readily observed that in all of these positions, women are in the minority. Over the years, the administrative role of schools has been considered the preserve of men. There has been a glass ceiling which women come in contact with when working up the corporate ladder (Morrison \& Glinow, 1990).

It can be realized that the slow progress of women faculty within the 
universities compared to men raises concern and needs investigating. The purpose of the study was to investigate the various barriers that hinder the progress of Ghanaian women faculty towards the leadership position in the public universities. To explore the barriers to the progress of women faculty towards university leadership, this study will address the following research questions.

1. What are the barriers that impede women faculty members progression toward leadership positions?

2. What are the effects of barriers to the progress of Women faculty towards leadership positions?

3. What leadership roles, do female faculty members aspire to?

A hypothesis was formulated to test whether there were significant differences in the means of barriers in the six public Universities in Ghana.

Ho: There are no statistically significant differences between the means of the barriers to the progress of women faculty of the different public universities in Ghana

HI: There are statistically significant differences between the means of the barriers to the progress of women faculty of the different public universities in Ghana.

\section{Method}

The research design, which was a descriptive survey, employed the quantitative research paradigm to explore the barriers to the progress of women faculty in the public universities in Ghana. Quantitative (questionnaire) data were analyzed for results. A multi-cited case study research design was appropriate for the phenomenon under investigation as the population and sample were selected from the six public universities in Ghana.

\section{Population}

Women faculty in KNUST, UCC, UEW, Legon, UDS and UMAT make up the population for the study. The study population consisted of 257 women faculty from six public universities in Ghana. Twenty women faculty were used to pilot the Questionnaire for Women Faculty (QFWF). The remaining 237 faculty constituted the study population.

\section{Sample and Sampling Procedure}

The census was the sampling technique used. Thus, apart from women faculty who were part of the pilot testing (20), the rest (237) made up the sample. Out of this number, 148 completed and returned a usable questiơnnaire.

\section{Instruments}

The instrument used for data collection was a questionnaire which was chosen with the research questions in mind. The Questionnaire for Women Faculty (QFWF) consisted of four sections with a total of 17 items, which had both closed and open-ended items. Section A solicited demographic data. Section $B$ considered barriers for women faculty in their professional advancement towards leadership positions. The response options ranged from 1 
(Not at all) to 5 (To a very large extent) for the five-point Likert-Like scale. Items in Section $\mathrm{C}$ were designed to reveal information on problems that barriers created for women faculty. Section D inquired about leadership roles female faculty members aspire to. A hypothesis was formulated to test whether there were significant differences in the means of barriers in the six public Universities in Ghana. A pilot testing was conducted using 20 women faculty from the various universities who were not part of the sample.

\section{Analysis and Results}

The purpose of the study was to seek answers to the barriers women faculty encounter as they progress within the university system. Analysis and results are discussed under the various research questions.
Research Question 1: What are the barriers that impede female faculty members' progression toward leadership positions?

Women faculty provided responses to items related to barriers to their progress within the university system. Means and standard deviations of the numerical responses of all items were generated and a single item mean weight (MW) of the overall mean was further calculated by dividing the overall mean by the total number of barriers listed in the question. The response scale of 5 (To a Very Large Extent), 4 (to a Large Extent), 3 (to a Little Extent), 2 (to a Very Little Extent), and 1 (not at all) was used to describe the degree of manifestation. The responses to this question are reported in Table 3.

Table 3: Barriers to the Progress of Women Faculty

\begin{tabular}{lcc}
\hline Barriers & Mean & Std. Deviation \\
\hline Lack of non-discriminatory policies in the work place & 3.29 & 1.26 \\
University culture & 3.32 & 1.06 \\
Cultural beliefs & 3.44 & 1.15 \\
Lack of years of experience in the university & 3.46 & 1.22 \\
Lack of female role models & 3.46 & 1.28 \\
National culture & 3.52 & 1.03 \\
Female socialization practices & 3.55 & 1.18 \\
Lack of involvement in professional organizations & 3.57 & 1.21 \\
Gender stereotypes & 3.62 & 1.04 \\
Lack of support from family members & 3.65 & 1.23 \\
Average mean of barriers: Section C & 3.70 & 0.59 \\
Role conflict & 3.84 & 1.21 \\
Lack of network of associates & 3.87 & 1.05 \\
Lack of a mentor or mentors & 3.93 & 1.31 \\
Lack of professional development opportunities & 4.14 & 1.04 \\
Lack of funding for research & 4.21 & 0.92 \\
Lack of publications & 4.44 & 0.88 \\
\hline Total & 148 & $\mathbf{1 0 0 \%}$ \\
\hline
\end{tabular}


As indicated in Table 3, to a large extent $(M=3.70, S D=0.59)$, the list of barriers negatively affect the progress of women faculty in their universities. The lack of professional development, lack of funding for research, lack of publications, role conflict, lack of retwork of associates and lack of mentors which were above the mean, were the greatest barriers to the progress of women faculty. Hirsch, Kett, and Trefil, (2002), Hammer and Thompson (2003), and Barnett (1998) all identified role conflict as a barrier to the upward mobility of women. Role conflict is a situation in which two or more job requirements are incompatible (Hirsch, Kett, \& Trefil, 2002). They further contend that the conflict may also be caused by a division of loyalties between the two roles.

According to Makhubu (1998), an academic is seen as a gender neutral individual who had the right qualifications for employment. Therefore, there are no special measures in place to support women during the intensive period of childbearing and childrearing. The university's ostensible neutrality on these matters ignores critical differences between men and women, thus putting women at a disadvantage, "making it extremely difficult for them to devote the kind of time required for excellence in research and scholarship. For many, it becomes a choice between family and career" (p. 129). This explains the inability of women in most cases to satisfy the promotions criteria of universities, many of which are based on strong research.

Lack of mentors is an issue that besets most women faculty as there are not many of them within the higher professional ranks and leadership positions (Tables land 2). On the other hand, cross-gender mentoring can also become a problem for them. This has been expressed by Hansman (1998), when he indicated that women are likely to have more difficulty initiating and maintaining mentor relationships in male-dominated institutions because of the perception of inappropriate relationships created when a woman seeks a male mentor, which creates sexual tensions in the mentoring relationships, and office gossip about mentor-mentee pairings.

Research Question 2. What are the effects of barriers to the progress of Women faculty towards leadership positions? The analysis is presented in Table 4.

Table 4: Effects of Barriers for Women Faculty

\begin{tabular}{lcc}
\hline Problems & Frequency & Percent \\
\hline Lack of Promotion & 59 & 39.9 \\
Lack of leadership positions & 33 & 22.4 \\
Pressure for time & 33 & 22.4 \\
Discrimination towards women within the system & 12 & 8.0 \\
Marital strain & 11 & 7.3 \\
\hline Total & $\mathbf{1 4 8}$ & $\mathbf{1 0 0 . 0}$ \\
\hline
\end{tabular}


The most serious problem identified in Table 4 was the lack of promotion which automatically prevents women from acquiring leadership roles and might make women feel being discriminated against. This brings to the fore the importance of research and publishing, which is a big issue for women faculty. There is the need for women to be involved in research to enable them publish good papers. articles and books if they have leadership aspirations. Adler (1999) indicated that women who choose to combine marriage with career face a difficult situation and they hardly know how to apportion time and resources between these two major responsibilities. The lack of senior women faculty is frequently explained in terms of women's decision to prioritize family over career (Krais, 2002). According to Manuh, Gariba, and Budu ( 2007), though conditions do not force a stark choice between work and family, they were not usually compatible. This means that, they have to be able to multitask so that women faculty can participate in activities both academic and social and serve their community. According to Currie, Thiele and Lewis (2002), the two "greedy" institutions, university and family, are time consuming and require women to stretch themselves to meet the demands of each.

Research Question 3: Do you aspire to advance to leadership positions in the university? Table 5 outlines the responses of respondents

\section{Table 5: Aspiration to Leadership Positions by Women Faculty}

Women faculty aspiring for leadership positions were $65.5 \%$. However, $34.5 \%$ of women faculty indicated they did not aspire to any leadership position. A follow-up question brought out varied reasons why about a third of respondents did not aspire for leadership positions. A majority of $55 \%$ of respondents indicated that they did not want to be in any leadership position because they could not conveniently combine their family and academic roles. This has support from

\begin{tabular}{lll}
\hline Response & Frequency & Percent \\
Yes & 97 & 65.5 \\
No & 49 & 34.5 \\
Total & 148 & 100.0
\end{tabular}

Hall (1996), who contents that administrative positions demand nearly total immersion, long hours, many evening meetings, and high personal visibility. A reason given by $35 \%$ of respondents was that they did not have any chance of any leadership role within their universities because of their age, as they were either almost near retirement or the number of years left will realistically not make it possible for them to get into any leadership position. However 10\% indicated that their low professional 
level will not allow them to be Leadership positions which $65 \%$ of considered for any leadership position. This is caused by lack of research and publishing. As Foster (2001) noted. promotion systems still largely rely on research output and publication records of candidates, although the stated criteria include excellence in teaching, and community work. Women are thus promoted less often than men and this is hardly surprising given their multiplicity of roles. "The greater demand on academic women's time hinders research productivity and reduces chances for progress" (p. 72). women faculty aspire to are presented in Table 6.

\section{Table 6: Aspired Leadership Positions of Respondents}

Table 6 brings out the fact that women faculty aspire for all leadership positions open to members of academia, even to the highest one (VC, $11.7 \%$ ). A majority of the 97 women faculty who aspire for leadership positions wanted to be deans $(31.9 \%)$ or HoDs $(30.8 \%)$. Although $6.0 \%$ indicated that they aspire for leadership

\begin{tabular}{lcc}
\hline Positions & Frequencies & Percent \\
Dean & 31 & 31.9 \\
HoD & 30 & 30.8 \\
VC & 11 & 11.7 \\
ProVC & 19 & 19.6 \\
Undecided & 6 & 6.0 \\
\hline Total & 97 & 100.0 \\
\hline
\end{tabular}

positions in future, they were undecided about the particular position.

\section{Results of Hypotheses Test}

Ho: There are no statistically significant differences between the means of the barriers to the progress of women faculty of the different public universities in Ghana.

H1: There are statistically significant differences between the means of the barriers to the progress of women faculty of the different public universities in Ghana.
The one-way ANOVA was conducted to test whether there were significant differences in the mean of barriers to the progress of women faculty in the six public universities of Ghana. The results are presented in Tables 7 and 8 . The descriptive statistics made up of the means (M), standard deviation (SD), the sample and the confidence intervals of the various institutions are presented in Table 7. 
Table 7: Descriptive Statistics for Barriers of Women Faculty

Table 8: One-Way Analysis of Variance for Mean Differences of Barriers for Women Faculty of the Six Public Universities in Ghana
With alpha level of .05, there were no statistical significant differences in the means of the barriers to the progress of women faculty of the various universities in Ghana, $F(5,142)=$ $.696, p=.627$. Thus the researcher failed to reject the null hypothesis.

\begin{tabular}{lcrrl}
\hline University & M & SD & $n$ & $\begin{array}{c}\text { Confidence } \\
\text { Interval }\end{array}$ \\
\hline Legon & 3.72 & 1.17 & 50 & $3.39,4.06$ \\
KNUST & 3.76 & 1.08 & 36 & $3.40,4.12$ \\
UCC & 3.68 & 1.13 & 29 & $3.36,4.13$ \\
UEW & 3.53 & 1.11 & 24 & $3.05,4.00$ \\
UDS & 3.88 & 99 & 6 & $2.83,4.93$ \\
UMAT & 3.67 & 94 & 3 & $1.58,5.76$ \\
\hline Total & $\mathbf{3 . 7 0}$ & $\mathbf{1 . 0 7}$ & $\mathbf{1 4 8}$ & $\mathbf{2 . 9 3}, \mathbf{4 . 5 0}$ \\
\hline
\end{tabular}

\begin{tabular}{lrclcc}
\hline Source & $\begin{array}{l}\text { Sum of } \\
\text { Squares }\end{array}$ & $d f$ & $\begin{array}{l}\text { Mean } \\
\text { Square }\end{array}$ & $F$ & Sig. \\
\hline Between Groups & $\begin{array}{r}344.901 \\
\text { Within Groups }\end{array}$ & 5 & 68.980 & .696 & .627 \\
\hline
\end{tabular}

\begin{tabular}{lll}
\hline Total & 14413.297 & 147
\end{tabular}

This implies that women faculty within the various public universities had common barriers which hindered their progress toward leadership positions.

\section{Conclusions and Recommendations}

Women faculty in all the public universities in Ghana have common barriers and problems which they have to strive to overcome. Most of them aspire for leadership positions such as the Deanship, HoDs, Pro-Vice Chancellors and the Vice Chancellorship. This proves that even in a male dominated environment, women still have hopes of advancing to leadership positions. There is the need for women to support and be each other's keeper, as they are in a patriarchal system where women are marginalized. 
Recommendations were made for both institutional leadership and women faculty.

\section{Institutional Interventions.}

To close the gender gap, it is important that women be made part of decision making bodies in the universities and redress structural barriers that influence the access and participation of both sexes, and women's active role in decision-making in the management and administration of universities. Junior faculty must also be offered the opportunity and responsibility of serving on different committees within and outside their faculties, as part of the socialization process in academia. This will help them develop their leadership potential and learning the ropes in higher education. Universities should find ways to empower women faculty. University leadership, HoDs, Deans, administrators, should support women who aspire to move up the academic ladder instead of frustrating them. Finally, employment equity policies should be fairly implemented so as not to disadvantage one group over another, or special favors extended to any special group of people. The leadership of universities should put in place interventions or actions that will reduce women's overall labor, as they combine their family roles with their career. For example, the provision of crèches (day nurseries) and primary schools on campus which can take care of children until women faculty are ready to go home will be an incentive to encourage the investment of more time in their academic career.
Recommendations for women Faculty.

There is the need for women faculty to plan early for career advancement, especially because the child-bearing phase normally affects their academic progress. If they plan around their multiple roles, they can survive within the academic environment and even afford to take up leadership positions. The need to develop a good research and publication profile is essential and a good step towards any leadership position. Women should not expect to be recognized and promoted just because they are competent, diligent, have talents and make contributions. They need to research and publish, so as to upgrade their curriculum vitae. Since the study revealed that women faculty in all six universities have common barriers, they can network together and find practical solutions to their common problems and seek encouragement from each other. In support, Johnsrud and Rosser (2000) intimated that not only do such networks provide opportunities for women to share experiences and offer support, but they also "allow a shift away from the male-centered academy. This shift allows women to engage with other women to create their own connections, which are separate from men, to decrease their isolation and build a power base" ( $p$. 124).

\section{References}

Adler, N. J. (1999). Global leaders: Women of influence. Thousand Oaks, C.A: Sage.

Belenky, M. F., Clinchy, B. M., Goldberger, N. R., \& Tarule, J. M. (1997). Women's ways 
of knowing. NY: Basic Books.

Brown, S. G., \& Barbosa, G. (2001). Nothing is going to stop me now: Obstacles perceived by low-income women as they become self-sufficient. PublicHealth Nursing, 18(1), 364-372.

Currie, J., Thiele, B., \& Harris P. (2002). Gendered universities in globalized economies: Power; careers and sacrifices. Lanham, MD: Lexington Books.

Foster, N. (2001). A case study of women academics' views on equal opportunities, career prospects and work-family conflicts in a UK University. Career Development International, 6, 28-38.

Hall, V. (1996). Dancing on the ceiling: A study of women managers in education. London: Paul Chapman Publishing

Hansman, C. A. (1998). Mentoring and women's career development. New Directions for Adult and Continuing Education, 18,63-70.

Hirsch, Kett, and Trefil (Eds) (2002).

The new dictionary of cultural literacy (3rd ed.). USA: Houghton Mifflin Company.

Johnsrud, L. K., \& Rosser, V. J. (2000). Understanding the work and career paths of midlevel administrators. San Francisco: Jossey-Bass.

Krais, B. (2002). Academia as a profession and the hierarchy of the sexes: Paths out of research in German univer- sities. Higher Education Quarterly, 56,407-418.

Makhubu, L. P. (1998). The right to higher education and equal opportunity particularly for women: The challenge of our time. Dakar: UNESCO Breda.

Manuh, T., Gariba, S., \& Budu, J. (2007). Change and transformation in Ghana's publicly funded universities. Oxford: Woeli Publishing House.

Morrisson A. M., \& Von Glinow M.A., (1990). Women and minorities in $\mathrm{manage}$ ment. Journal American Psychologist, 45(10), 200208.

Stephenson, M. B., \& Burge, P. L. (1997). Eliciting women's voices: Vocational choice and educational climate for women in nontraditional occupational programs. Journal of Vocational Education Research, 22(I), 153-171

Swanson, J. L., \& Woitke, M. B. (1997). Theory into practice in career assessment for women: Assessment and interventions regarding perceived career barriers. Journal of Career Assessment, 5(1), 443-462.

Wylie, J. C. (1996). Chances \& choices: How women can succeed in today's knowledge-based business. Vienna, VA: EBW Press. 